\title{
VIOLÊNCIA OBSTÉTRICA: O RELATO DE UMA DOR
}

\author{
OBSTETRIC VIOLENCE: THE REPORT OF A PAIN
}

Ingridy Mayara da Silva Leite'

Daniela Heitzmann Amaral Valentim de Souza ${ }^{2}$

\section{RESUMO}

Ao longo do tempo o parto perdeu a configuração de um evento eminentemente fisiológico e ganhou diversas intervenções médicas, essas condutas foram sendo enraizadas na prática do profissional que auxilia a parturiente, no entanto, o excesso de procedimentos medicalizados podem trazer inúmeros prejuízos a saúde física e emocional da mulher, principalmente porque retira da mesma o protagonismo neste evento. Entendemos como violência obstétrica todo e qualquer ato ou procedimento violento e/ou ineficaz utilizado para com a mulher no momento da parturição. Dessa forma, o objetivo desse estudo visou compreender as consequências físicas e emocionais decorrentes da violência obstétrica. De natureza qualitativa, o estudo de caso em questão, contou com a participação de uma mulher que vivenciou a experiência de violência no parto, para coleta de informações foi utilizada uma entrevista semiestruturada composta de questões que trouxeram características psicológicas advindas do seu processo de parturição. Foi possível perceber as dores e o sofrimento vividos pela participante da pesquisa no seu parto, pós-parto e até os dias atuais, sendo assim, constata-se que as consequências da violência obstétrica podem deixar traumas que se perpetuam durante anos, haja vista que é destinada a autonomia e feminilidade da mulher, ou seja, não se limita apenas a maternidade.

Palavras-chave: Violência Obstétrica. Parturição. Parto violento. Humanização no parto.

\begin{abstract}
Over time the child lost the configuration of an eminently physiological event and gained several medical interventions, these behaviors were being rooted in the practice of the professional who helps the parturient, however, the excess of medicalized procedures can bring innumerous damages to physical health

1 Graduada em Psicologia pelo Centro Universitário de João Pessoa (UNIPÊ). Pós-graduanda em Saúde Materno-Infantil pela Faculdade Unyleya. E-mail: ingridy-msl@hotmail.com

2 Doutora em Psicologia Social pela Universidade Federal da Paraíba (UFPB). Docente do Centro Universitário de João Pessoa (UNIPÊ). E-mail: daniela.heitzmann@unipe.br
\end{abstract}


and emotional state of the woman, mainly because it removes of the same the protagonism in this event. We understand as obstetric violence any and all violent and / or ineffective acts or procedures used with women at the time of parturition. Thus, the objective of this study was to understand the physical and emotional consequences of obstetric violence. Of qualitative nature, the case study in question was attended by a woman who experienced the experience of violence in childbirth. A semistructured interview was used to collect information, which was composed of questions that brought psychological characteristics from the process of parturition. It was possible to perceive the pain and suffering experienced by the research participant in their delivery, postpartum and even today, and it is observed that the consequences of obstetric violence can leave traumas that are perpetuated for years, since is destined for the autonomy and femininity of women, that is, it is not limited only to motherhood.

Keywords: Obstetric Violence. Parturition. Violent childbirth. Humanization in childbirth.

\section{INTRODUÇÃO}

O parto se constitui um evento que paira no imaginário da grávida durante o decorrer da gestação e vai sendo idealizado por ela. É um processo rodeado de significados, expectativas e transformações físicas e psicológicas. De acordo Davis-Floyd (1994) na Antropologia médica, essa vivência é definida como um rito de passagem diante de sua riqueza simbólica e pela redefinição da posição dessa mulher nos âmbitos social e familiar. Entende-se que esse é um evento de separação entre o corpo do bebê daquele que o gerou, sendo esse um processo dotado de sentimentos que afetam o psicológico da mãe.

Desde a Antiguidade o processo de parturição possui uma importância significativa na vida da mulher, mencionados desde os escritos bíblicos, onde a dor foi vinculada a esse momento quando Eva ingere o fruto proibido e tem como castigo por seu pecado a dor multiplicada. A Sagrada Escritura cita que essas dores são punições que a mulher deve sentir por ter cometido o pecado original, interferindo em seus sentimentos e percepções acerca deste momento, substituindo o sentimento de prazer durante a concepção pelo castigo (BEZERRA; CARDOSO, 2006). A interpretação ingênua dessa passagem bíblica foi se perpetuando ao longo da história e firmando a ideia de que o parto é um momento de dor e sofrimento e que esta condição deve ser aceita pela mulher como inerente, tal pensamento também pode ter sido transferido e enraizado na prática médica.

Em pesquisa demandada pelo Ministério da Saúde ao Conselho Nacional de Desenvolvimento Científico e Tecnológico (CNPq), o Projeto Nascer no Brasil realizou um estudo entre os anos de 2011 a 2012, a qual teve por objetivo analisar 
as intervenções obstétricas em mulheres de risco habitual e utilizou uma amostra de 23.940 mulheres, o resultado foi surpreendente, em apenas $5,6 \%$ dos partos não houve nenhuma intervenção obstétrica, ou seja, em quase $95 \%$ dos casos houve a violência obstétrica (BRASIL, 2012)

Como se pode identificar, o número de casos que contém algum tipo de procedimento que indica que houve a Violência Obstétrica é alarmante, se constituindo uma questão de saúde pública. Deve-se atentar ainda para o fato de que esse tipo de violência é singular, pois pode não haver sinais visíveis e na maioria das vezes a mulher acredita que o procedimento foi o correto, sendo considerado próprio da gestação e do parto. Esses procedimentos desnecessários muitas vezes são traumáticos e podem transformar um evento tão desejado pela mulher em um que traz sentimentos negativos, tendo sido denominado pela literatura de Violência Obstétrica.

\section{VIOLÊNCIA OBSTÉTRICA: DO QUE SE TRATA?}

Antes de qualquer estudo sobre o tema se faz necessário conhecer sua definição. Segundo Juarez, et al. (2012) esse termo aborda qualquer ato exercido por profissionais da saúde no que cerne ao corpo e aos processos reprodutivos das mulheres, utilizando a atenção desumanizada, abuso de ações intervencionistas, medicalização e a transformação patológica dos processos de parturição fisiológicos. De acordo com Wolff e Waldon (2008) as mulheres submetem-se a tal ato devido algumas questões, tais como a condição de desigualdade entre médico e paciente, ao desconhecimento do processo fisiológico do parto, por falta de informações acerca das melhores práticas de assistência, por temerem pela sua vida e a do bebê ou por acreditarem que aquelas são as condutas adequadas.

Constata-se que, até o século XVIII o parto era realizado por parteiras no domicílio da mãe tendo só no fim do século XIX passado por mudanças tornandose prática médica. No século XX quase $90 \%$ dos partos já eram realizados em hospitais (RATNER, 2009). Aliado a este fato ocorreu também o aumento no uso de tecnologias com o objetivo de "iniciar, intensificar, regular e monitorar o parto, tudo para torná-lo 'mais normal' e obter ganhos para a saúde da mãe e do bebê" (DINIZ; CHACHAM, 2006, p91). Contudo, contrariando o objetivo inicial, a medicalização do parto e o uso de procedimentos considerados inadequados e desnecessários podem colocar em risco a saúde da mãe e do bebê. Além disso, segundo Leister (2011) o desenvolvimento do conhecimento cirúrgico e tecnológico fez a mulher sair do papel de protagonista e ocupar o de coadjuvante no processo de parturição.

O parto se caracteriza como um processo fisiológico necessitando, na maioria dos casos, de apoio e atenção. O corpo se prepara para este evento, o colo do útero se dilata e se contrai para que haja a saída do bebê, é um processo fisiológico e inicia-se pela liberação de hormônios, dentre os quais, a ocitocina que 
é responsável pelas contrações no útero e as endorfinas que atenuam a sensação de dor, porém qualquer situação que fomente a liberação de adrenalina, ou hormônio similar, pode inibir o processo (CARVALHO et al., 2012).

De acordo com Osis (1998) em 1970 movimentos feministas iniciaram uma onda de reinvindicações no sentido de transformar a atenção oferecida à mulher, a mesma era vista de forma reducionista e fragmentada com ações focadas para gerar filhos sadios. Esse movimento apelava por incorporar à saúde da mulher outras questões, como pré-natal, melhores condições ao parto e, ainda, outros aspectos relacionados ao gênero, trabalho, sexualidade, saúde, anticoncepção e a prevenção de doenças sexualmente transmissíveis. Essa organização feminista e suas reinvindicações permitiu a criação das diretrizes do Programa de Assistência Integral a Saúde da Mulher (PAISM). O programa, criado pelo Ministério da Saúde em 1983, é considerado um marco na luta por assistência humanizada no parto e visou atender a mulher de forma integral (BRASIL, 2004).

Durante as décadas de 1980 e 1990 vão se fortalecendo os estudos sobre o modelo de parto no Brasil, o mesmo baseava-se em ações intervencionistas e medicalizadoras. Com o objetivo de transformar esse cenário, o Ministério da Saúde lança medidas para valorizar o parto normal, tentando resgatar esse evento como fisiológico, uma dessas medidas foi o aumento de $160 \%$ na remuneração do parto vaginal e o pagamento de analgesia do parto buscando diminuir as altas taxas de cesarianas (BRASIL, 2000).

Em 1996, a Organização Mundial da Saúde desenvolve uma classificação em relação às práticas utilizadas na condução do parto normal, orientando quanto às condutas adequadas e as inadequadas durante a parturição. Dentre as práticas que devem ser realizadas estão: o plano individual de cuidado, o respeito à escolha das mulheres sobre os mais variados procedimentos, que vão desde a escolha do acompanhante até a melhor posição, o fornecimento de informações claras e o uso de métodos não farmacológicos para alívio da dor, tais como massagens e técnicas de relaxamento (OMS,1996)

Em relação às práticas prejudiciais se enquadram: o uso rotineiro de enema, a tricotomia, a episiotomia, a posição litotômica, como práticas que devem ser utilizadas com cautela está: o uso rotineiro da ocitocina, e ainda, como práticas usadas de modo inadequado estão: a restrição hídrica e alimentar, o controle da dor por analgesia peridural, a mudança na dinâmica uterina com utilização da ocitocina e exames vaginais em demasia (OMS, 1996). Tal diretriz passou por algumas atualizações, a última ocorreu em 2018 e foi nomeada de "Modelo de cuidados intraparto da OMS" e além de delimitar as intervenções que são adequadas ao parto, também discorre sobre o tratamento destinado a mulher em trabalho de parto, visando de forma mais clara devolver a autonomia e o protagonismo desse momento a ela (OMS, 2018). 
Vale ressaltar que o termo humanização foi adotado somente em 2000, quando foi lançado o Programa Humanização do Pré-Natal e Nascimento (PHPN), por meio da Portaria GM n. 569, de 1\%/06/2000. O programa tem por prioridade promover a melhoria do acesso, da cobertura e da qualidade do acompanhamento do pré-natal, da assistência ao parto e ao puerpério para o binômio mãe-filho, visando ainda retomar o caráter fisiológico e natural do parto, resgatando o protagonismo da mulher nesse momento (BRASIL, 2000).

Apesar de todas as medidas tomadas com o objetivo de atenuar as intervenções e retomar o caráter fisiológico do parto, ainda hoje o número de procedimentos desnecessários é exorbitante. Segundo Leal et. al. (2014) o número de intervenções é considerado excessivo e não encontra respaldo científico em estudos internacionais. Muitos desses procedimentos podem causar risco e complicações, além de serem dolorosos, sendo seu uso considerado desnecessário, como é o caso da episiotomia.

\section{MANIFESTAÇÕES DA VIOLÊNCIA OBSTÉTRICA E CONSEQUÊNCIAS}

Pode-se afirmar que a violência obstétrica está instalada no processo de parturição, apesar de todos os movimentos realizados contra essa realidade, esse fato se comprova pelo número de intervenções equivocadas que são realizadas no momento de parturição, mas o que determina essa violência, ou ainda, quais os procedimentos são inadequados a este momento?

De acordo com Cunha (2015) assim que a gestante chega a unidade de saúde em trabalho de parto lhe é aplicado o acesso para introdução do soro intravenoso, com a justificativa de que será um meio de hidratação e também de facilitação na aplicação de medicamentos que possam vir a ser necessários. No entanto, o mesmo autor explica que a aplicação venosa é uma prática desnecessária em partos de via natural. O Dossiê da Violência Obstétrica lançado em 2012 pelo Senado Federal diz ainda que o uso do soro intravenoso é prejudicial no sentido de dificultar a preambulação da parturiente, o que leva a uma perda da autonomia e de relaxamento do corpo (BRASIL, 2012).

O acesso intravenoso é realizado para que haja a facilitação da aplicação da ocitocina sintética. Rezende e Montenegro (2013) alegam que a ocitocina acelera o trabalho de parto, aumentando a intensidade e a frequência das contrações uterinas. Este motivo leva ao uso indiscriminado da ocitocina, de acordo com a pesquisa Nascer no Brasil (2014) o uso de tal substância é de 38,2\% nos partos de baixo risco, $33,3 \%$ em risco obstétrico e $30,4 \%$ em todas as mulheres. No entanto, o uso da ocitocina deve ser ponderado, pois de acordo com Souza et al. (2010), o aumento das contrações pela sua aplicação causa uma dor muito mais intensa que pode levar a uma ruptura do útero devido ao grau das contrações. Além disso, as consequências da administração errada da ocitocina poderão implicar em 
complicações da indução e podem ainda incluir infecção intracavitária, prolapso de cordão umbilical, prematuridade iatrogênica, sofrimento ou morte fetal e falha da indução.

Outro procedimento utilizado em demasia é a amniotomia. De acordo com a pesquisa Nascer no Brasil (2014), a porcentagem é de 40\%, sendo aceito como método para acelerar o trabalho de parto, quando o mesmo possui um tempo superior ao natural. O método é feito pela introdução de um pequeno gancho que rompe a bolsa amniótica, o que permite a saída do líquido amniótico, acelerando o processo de parturição (OBERG, 2010).

Em relação a melhor posição para o parto foi lançada a Portaria nº 1.067 de 2005, que determina que a decisão da mulher sobre a posição deve ser respeitada. No entanto de acordo com a pesquisa Nascer no Brasil (2014) em 92\% dos partos realizados a posição litotômica ou ginecológica (deitada com a face para cima e joelhos flexionados) é utilizada. Isso nos faz inferir que as mulheres na prática não possuem real poder de escolha nesse momento, não existe uma indagação da posição mais confortável, a qual poderia levar a um nível de relaxamento, facilitando o processo de parto.

A manobra de Kristeller (aplicação de pressão na parte superior do útero), apesar de proscrita, está presente na assistência ao parto em cerca de $37 \%$ dos casos (LEAL et al., 2014). A força sobre a barriga não tem como ser dosada. Esse procedimento leva a ocorrência de um alto número de partos distócicos por ventosas, e também contribui para a elevação dos índices da realização da episiotomia e lacerações de períneo (CARVALHO et al., 2012).

A episiotomia se trata de um corte na vulva e na vagina feito com uma tesoura ou bisturi comumente chamado de "pique" ou "episio" no intuito de facilitar a saída do bebê, a qual visa tornar a parturição mais rápida e evitar lacerações dos tecidos do canal do parto. É um procedimento cirúrgico realizado rotineiramente no parto vaginal apesar de não possuir embasamento em evidências científicas essas afirmações são encontradas no Dossiê da Violência Obstétrica, lançado pelo Senado Federal em 2012 e produzido por uma rede de mulheres brasileiras que lutam contra a violência obstétrica, o programa é denominado Parto do Princípio (BRASIL, 2012).

A utilização habitual da episiotomia pode levar a uma série de complicações, dentre as quais, o risco de infecção e erro cirúrgico, hematoma, rotura de períneo, dispareunia, deiscência, abcesso, incontinência de gases e fezes, fístula retovaginal e lesão do nervo pudendo. Os riscos subsequentes incluem a extensão da lesão, hemorragia significativa, dor no pós-parto, edema, e mais raramente a endometriose da episiorrafia. Vale destacar que além dessas complicações o procedimento pode ocasionar alterações cicatriciais para o resto da vida (ZANETTI et al, 2009). Cicatrizes essas que podem dificultar na vida sexual da mulher, pois de acordo com Chaú 
(1991) os órgãos genitais são privilegiados na sexualidade adulta, especialmente porque se trata de parte do corpo cercada de representações e simbolismos.

No Brasil, muitos profissionais de saúde continuam a realizar o procedimento por hábito e pelo mito de que o corte vai preservar o prazer masculino. $\bigcirc$ uso rotineiro da episiotomia começou a ser defendido em 1895, por Stahl, que argumentava que a episiotomia permitia uma melhor restauração do períneo em relação às lacerações perineais. No entanto, de acordo com Costa (2001) alguns estudos apontam consideráveis desvantagens na utilização habitual da episiotomia, tais como necessidade de reparo cirúrgico, perda sanguínea, custo alto, desconforto materno e posterior alterações na função sexual. Ainda, segundo Diniz (2004) a episiotomia de rotina é considerada por vários autores como uma forma de mutilação da genitália feminina, uma violência de gênero cometida pelas instituições e profissionais, além disso, se trata de uma questão de desrespeito aos direitos humanos na área de saúde.

Além dessas intervenções medicalizantes, as mulheres podem ser submetidas a outras situações desconfortantes, tais como restrição hídrica e alimentar, ausência de esclarecimentos sobre os procedimentos e a negação ao direito de acompanhante à sua escolha. De modo geral, as unidades de saúde obrigam jejum total às grávidas, o que é incoerente, pois o trabalho de parto exige muita energia, devido às contrações uterinas e a duração natural do evento, sendo assim, a fraqueza e debilitação dificultará o trabalho de parto (CUNHA, 2015).

De acordo com Rezende e Montenegro (2014) no hospital, a mulher é separada de tudo que lhe cause a sensação de conforto para adentrar no ambiente médico, ela permanece à disposição do profissional e propensa às intervenções cirúrgicas. Odent (2003) corrobora com esta posição ao afirmar que ao chegar em trabalho de parto em uma unidade de saúde a mãe se depara com inúmeros medos, podemos chamar a atenção para o ambiente onde ocorre o parto, a sala cirúrgica, com temperatura baixa, inúmeros objetos e aparelhos que em nada se assemelham ao ambiente familiar. Os profissionais e a dinâmica envolvida àquele ambiente também são atípicos. O mesmo autor ainda fala que esse medo provoca a secreção de doses elevadas de adrenalina e faz com que haja a inibição de ocitocina, hormônio responsável pelas contrações uterinas e consequente expulsão do bebê. Com isso vemos a importância de se fazer conhecer ainda em pré-natal os procedimentos realizados na parturição.

Como um evento fisiológico, durante o parto por via vaginal, o bebê percorre o canal com movimentos ativos. Em cada tempo, os movimentos do bebê vão moldando o canal vaginal de forma sincronizada, fazendo progredir o trabalho de parto. Este momento pode ser bastante prazeroso, constituindo uma expressão da sexualidade da mulher (PROGIANT; PENHA; CHRISTOFEL, 2004). No entanto Odent (2003) diz que quando o meio cultural interfere na fisiologia do parto, o faz também com a sexualidade. Sendo assim, quando há intervenções nesse momento a mulher 
não experimenta essa expressão da sexualidade. Os aspectos prazerosos de tal evento são aniquilados por procedimentos estressores provocados.

O momento do parto, de acordo Davis-Floyd (1994), é definido como um rito de passagem diante de sua riqueza simbólica, sendo assim, é um momento rodeado de significados e expectativas. Sendo um evento eminentemente fisiológico, salvo em raros casos, todo e qualquer procedimento externo e invasivo à fisiologia pode resultar em experiência dolorosa para a mulher, para o bebê e para ambos, o que leva a instalação do trauma. Rezende e Montenegro (2013) corroboram com esta afirmação ao concluir que para que o parto ocorra de forma satisfatória e tranquila, é imprescindível que seja resguardado o bem-estar físico e emocional da mulher, o que reduzirá os riscos e complicações resultantes de intervenções desnecessárias.

Diante do exposto, o artigo teve como objetivo geral compreender as consequências físicas e emocionais decorrentes da violência obstétrica segundo o relato de uma mulher que vivenciou essa experiência e como objetivos específicos: identificar a percepção da mulher sobre as condutas que caracterizam esse tipo de violência; relacionar os sentimentos experimentados e as necessidades sentidas decorrentes da mesma e; analisar os possíveis prejuízos na vida afetiva, emocional e social da mulher decorrentes dessa violência.

\section{METODOLOGIA}

Trata-se de um estudo de caso, de natureza qualitativa, no qual segundo Cajueiro (2015) possibilitaráum a profundamento desituaçõese fenômenos parecidos, contribuindo para a construção de novos modelos e procedimentos. Optamos pela pesquisa qualitativa por entender que essa metodologia é a mais apropriada aos objetivos do presente estudo. O investigador clínico-qualitativista não possui como objetivo demonstrar como um fenômeno se comporta numericamente, mas seu alvo de interesse são as significações/significados que um indivíduo ou grupo atribuem aos fenômenos da natureza que thes dizem respeito. Sendo assim, contempla o estudo da subjetividade ocupando-se com a elucidação e o conhecimento dos processos de significação que a constituem. "As significações são obtidas através da fala e do comportamento das pessoas ou da comunidade em estudo" (TURATO, 2011, p.361).

O estudo de caso foi realizado na cidade de João Pessoa - PB e contou com a participação de uma mulher que relata ter sido vítima de violência obstétrica. A participante foi escolhida através do critério de inclusão proposital, critério este, onde o pesquisador escolhe deliberadamente a participante que comporá o estudo de acordo com os objetivos do trabalho, desde que possam fornecer as informações pertinentes ao mesmo.

Com a obtenção da aprovação do Comitê de Ética em Pesquisa sob o parecer de $n^{\circ} 2.424 .666$ se iniciou a coleta de dados, onde foram utilizados os 
seguintes instrumentos: Questionário sociodemográfico e Entrevista semiestruturada, composta de questões que atendem aos objetivos propostos. Minayo (2014, p. 99) esclarece que a entrevista orienta "uma conversa com finalidade, servindo como facilitadora de abertura, ampliação e aprofundamento da comunicação" obtendo-se assim informações e opiniões pertinentes ao estudo.

Obedecendo a Resolução 466/12, do Conselho Nacional de Saúde, o qual garante sigilo, anonimato e consentimento informado aos participantes, o contato prévio com a participante se deu por telefone e no encontro presencial agendado foi the dada as informações sobre o estudo e esclarecida como seria sua participação, e feita a leitura do Termo de Consentimento Livre e Esclarecido, após ter concordado em colaborar fez a devida assinatura, foi ressaltado ainda que a mesma poderia desistir de participar em qualquer momento sem que houvesse qualquer prejuízo. Logo após foi solicitado os seus dados sociodemográficos e só então iniciamos a entrevista.

A entrevista foi realizada na residência da participante e o material obtido a partir dos instrumentos utilizados foram analisados de forma qualitativa, mais especificamente através da análise de conteúdo temática. Respeitando o sigilo ético o nome da participante foi substituído por nome fictício. A seguir se realiza a apresentação do caso, relatando o episódio no qual a participante relata ter sofrido a violência obstétrica.

\section{RESULTADOS}

Mariana, 39 anos de idade, Psicóloga, casada e tem uma filha que está com três anos de idade, nascida através de um parto normal, no qual relata ter sofrido a violência obstétrica.

A entrevistada conta que sua gravidez não foi planejada, mas desejada e havia idealizado um parto normal, tendo assim, buscado conhecer como esse ocorria. A partir da descrição e do relato da experiência vivida pela entrevistada, foi perceptível o quanto o processo de parturição de Mariana foi traumático. $\bigcirc$ início da gravidez foi tomado por algumas angústias visto que ela possuía segunda a sua percepção, uma idade não adequada para uma gravidez, outro aspecto importante para a eclosão de angústias foi o fato de ser de uma família tradicional e não ser casada, dessa forma tinha receio do modo que seus pais veriam essa gestação. Também no início da gravidez, foi acometida por urticária generalizada, e por diagnóstico errado de doença infectocontagiosa da médica ginecologista que até então the acompanhava, a mesma chega a ser consultada por nove diferentes médicos no mesmo dia, o que corroborou para que este início de gravidez fosse turbulento e inseguro.

Após procurar outro profissional que pudesse the acompanhar, diante do erro de diagnóstico do anterior, Ihe indicam uma médica que era conhecida por 
sua família, no entanto, a gestante era privada de informações por esta, sobre isso ela diz "ela nunca respondia claramente, ela nunca deixou claro o que eu queria saber!". Diante da ausência de informações, a assistência pré-natal prestada a esta gestante não foi adequada, além disso, o medo proveniente do pensamento de que sua idade não seria a ideal para a gravidez, permearam todos os meses da gestação, medo esse que não foi atenuado, mas alimentado já que a mesma não possuía informações claras sobre o fato.

Descreve a partir de então o seu parto, relata que entra em trabalho de parto por volta das quatro horas da manhã do dia primeiro de janeiro de 2015, liga para a médica e é aconselhada por ela a se dirigir a uma maternidade, ao chegar por volta das seis horas da manhã o médico plantonista entra em contato telefônico com a sua médica e este passa a mesma o estágio de parto em que Mariana se encontrava. Através do exame de toque realizado percebeu-se que possuía três cm de dilatação e com algumas contrações, portanto, ainda no primeiro estágio de parto. A médica que lhe acompanhava chegou à maternidade por volta das dez horas da manhã, e Mariana afirma que, neste momento tudo transcorria tranquilo, num percurso que culminaria na modalidade normal que tanto desejava. Na reconstrução da cena vivida, Mariana conta que a cada contração sentida falava "Tem calma filha, é assim mesmo, mamãe tá sentindo!" Afirma ainda que as enfermeiras ensinavam exercícios para aceleração do processo, traziam toalhas para secar o líquido que expelia e que em sua percepção julgava estar recebendo uma boa assistência, mas ao chegar aos nove cm de dilatação, estando no terceiro e último estágio para o nascimento do bebê, ela sente uma contração muito forte e suscita que não aguentará a dor.

No ápice dos nove $\mathrm{cm}$ de dilatação foi induzida a realizar uma analgesia, sem direito a escolha, sem entender o que estava acontecendo, como seria o procedimento e suas consequências. Percebe-se no relato apresentado que, apesar de todos os questionamentos feitos por Mariana sobre o procedimento, não foi the dada a oportunidade de escolha sobre fazer a aplicação medicamentosa, levando-a a uma sensação de apropriação de seu corpo por um terceiro, pois neste momento essa mulher perde a voz, não é ouvida e nem considerada. As soberanias das decisões médicas estão intrínsecas na cultura e, entender que o protagonismo deve ser dado à mulher, mesmo nos dias de hoje, permanece um desafio. Sobre o procedimento, ela diz:

"[...] eu me pergunto por que eu permiti fazer aquilo comigo, eu estava na dúvida, só que por mais que a gente tenha conhecimento a gente tá tão vulnerável, a gente tá num momento tão sensível. A partir desse momento eu passei a não sentir mais as contrações[...]."

O sentimento que definiu o momento vivido por Mariana e, que na realidade deveria ter sido uma ocasião de plenitude e alegria diante da expectativa do nascimento de sua filha, na realidade foi de "Desespero. Teve uma hora que eu 
pensei 'meu Deus, eu quero desmaiar aqui.' [...] para eles darem um jeito e eu não me responsabilizar mais por nada."

Neste trecho da entrevista é possível perceber que havia um sentimento de culpabilização da parturiente. Diante da pressão e da angústia a qual se encontrava, o medo de que não desse certo e de que perdesse sua filhinha, a fazia ter muito receio, pois se algo de errado ocorresse ela seria a culpada porque tinha escolhido o parto normal.

O momento expulsivo foi influenciado pela analgesia, ou seja, Mariana não sentia as contrações, não sabia se ajudava na expulsão do bebê, aliado a isto os batimentos cardíacos da criança estavam perdendo a vitalidade e a mãe num momento de desespero solicita que seja feita a manobra de Kristeller, mesmo sabendo que seu uso é inadequado. Sua fala é muito forte e marcante, sobre esse fato diz "nesse momento eu pedi para ser violentada.".

Nesse depoimento se verifica o quão degradante o nível em que foi levado o corpo dessa mulher. A opção foi vista, naquela ocasião, como uma forma de salvar a vida da sua filha, mas para que isso ocorresse o seu desejo, sua expectativa, sua tranquilidade, sua espera, sua sensibilidade e sua vontade, foram totalmente aniquiladas e ainda mais do que isto, levado ao extremo do não-pertencimento, naquele momento, não havia significado para ela, o seu corpo era um instrumento para que fosse facilitado a saída da bebe.

Diante dessa situação já tão difícil e angustiante a médica, que deveria resguardar e proteger sua paciente que confiou em seus "cuidados profissionais", ainda culpabiliza Mariana por ter feito tal escolha de via de parto, que para a médica foi errada, aconselhando-a a não realizar partos normais caso chegasse a engravidar novamente. O absurdo da fala de uma profissional, que insinuou uma culpa que não cabia a Mariana, responsabilizando-a por todo o ocorrido.

Durante a narrativa, são claras as diversas negligências que Mariana foi submetida. Uma primípara que não tinha conhecimento suficiente para enfrentar sozinha o parto e contava com os cuidados e a atenção de uma médica a quem depositou sua confiança, mas que desviou sua implicação com o que estava ocorrendo e a lançou a parturiente.

O outro forte momento vivido, que foi descrito pela participante, ocorre logo após o nascimento da bebê. Mariana permaneceu sem informações da filha por 6h, causando-Ihe extrema insegurança e dificultando a iniciação do vínculo com a filha, talvez por medo de ter que elaborar um luto. Uma elaboração pela possibilidade de perda concreta da filha que poderia vir a óbito, ou pela perda da expectativa criada de sua filha que poderia ter sequelas. Em ambos os casos, a culpa perseguia Mariana, pois na voz da "autoridade médica", ela havia feito uma escolha inadequada que trouxe prejuízos para a filha. Que situação desesperadora para uma mãe, num momento tão delicado e sensível. Quanta imprudência e 
insensibilidade de profissionais que deveriam zelar pelo melhor e pela plenitude de seus pacientes.

Identifica-se que as angústias e temores de Mariana foram intensificados diante dos eventos e das falas dos profissionais, pois ela inicialmente possuía um receio por conta da sua idade, então a insegurança era um sentimento presente nela que foi potencializado por não ter escolhido a via de parto adequada, e por este motivo o receio de que a filha pudesse ter alguma sequela ocasionada por suas escolhas e o sofrimento que isso traria a sua filha, apavoravam a participante.

"Me roubaram o direito não só de ter o parto que eu queria, mas de viver o amor pela minha filha depois que ela nasceu. [...] era como se todo amor que eu tinha construído durante a gravidez, no momento que ela nasceu acabou."

Talvez o que Mariana percebia como um amor que se esvaziou pela filha depois do nascimento, tivesse sido ao contrário, poderia ser um amor absurdo que não suportava ver o sofrimento que acreditava ter causado à filha. Então, o que inicialmente ela percebeu como "rejeição" fosse, na realidade, o desejo de isentar sua filha dos problemas, sequelas e dores. Uma tentativa de negar o que estava acontecendo diante do sofrimento que sentia, uma forma de dar vazão a dor que vivenciava ante a possibilidade de perder sua filha.

Mais um dos momentos marcantes relatados pela participante se refere ao médico pediatra que acompanhava sua filha. A forma hostil e inapropriada com que aquele profissional fala com Mariana, uma mãe que está longe de sua filha, sem notícias, sem saber o que está acontecendo, após um parto delicado, ele informa de maneira muito grosseira que atribuiu um Apgar 3 por muita bondade para a criança. O Índice de Apgar trata-se de uma avaliação do neonato que atribui pontuação de até 10 para os seguintes sinais: cor da pele, tônus muscular, respiração, frequência cardíaca e irritabilidade reflexa. Quanto menor a nota mais grave é o estado do bebê.

Além disso, ainda sofreu com a equipe de enfermagem, as orientações sobre a amamentação foram insuficientes. Imagina-se como esse encontro de colocar sua filha no colo e amamentar foi idealizado durante a gestação, e na realidade o que se identifica nesse estudo de caso é que esse direito foi dificultado e extirpado através de condutas e falas desnecessárias, punitivas e absurdas para uma equipe de saúde que alimentava a criança antes de levá-la a mãe, a pressão exercida sobre a participante de que ela sairia sem sua filha, pois essa não seria liberada se o movimento de sucção não estivesse ocorrendo satisfatoriamente. Mais um elemento estressor que poderia estar dificultando a liberação do leite materno.

Além de todos esses eventos apontados até então, ainda foi citado pela entrevistada a falta de sensibilidade e de estrutura do hospital para mães que passam por dificuldades com seus bebês que precisam ir para a UTI Neonatal. Esse local e o berçário estão localizados um ao lado do outro, assim inevitavelmente 
a mãe para ir ver seu bebê tem que passar pelo berçário. Ficou num quarto em que havia outra mãe com seu filho nos braços, essa vizinha de leito estava experimentando e vivendo tudo aquilo que ela sonhou e se programou durante a gestação. Sendo assim, presenciava a felicidade de outros casais, de outras famílias sem poder experimentar essa alegria que, aliado as angústias que estava passando, aos pensamentos confusos e conflituosos que permeavam sua mente, tornavam a situação ainda mais complicada e insuportável.

Vários aspectos e falas dos profissionais colocavam e acentuavam na parturiente o sentimento de culpa. Lançavam-na a reviver a dor sofrida, o arrependimento em ter demorado a engravidar, a via de parto escolhida, o medo da perda, o temor em ter prejudicado sua filha. E mesmo diante de tantos conflitos, grita por ajuda, mas seu sofrimento foi descaracterizado. Foi-lhe negado o atendimento por um psicólogo, e o pior, a impressão que teve ao solicitar essa ajuda foi de ter sido ridicularizada pela equipe que a estava acompanhando no hospital.

Outro momento marcante descrito se refere a vida fora do hospital. $O$ sofrimento não se extinguiu com o retorno ao lar. Além de ter peregrinado por 30 dias a médicos para ver se sua filha estava com algum problema, e que de fato descobre que há sim, no entanto, não coloca em risco o seu desenvolvimento neurotípico. Apresentou depressão pós-parto, dificuldades para lhe dar com sua dor e seu sofrimento e, tempos depois, se deu conta de que o que sofreu foi violência obstétrica.

A descoberta dessa violência traz ainda dores, conflitos e culpa por ter se deixado passar por isso, por ter permitido que isso tenha ocorrido. Até hoje, depois de três anos do ocorrido, Mariana sofre pelos traumas advindos do momento de parturição. Apresenta receio em engravidar devido o pavor de ter a possibilidade de passar pela mesma experiência, que a impede de viver tranquila, sobre isso ela diz "[...] eu não relaxo em nenhum momento, porque eu ali estou vulnerável a uma gravidez e eu ainda não me recuperei, então atrapalha, eu poderia estar vivendo mais plenamente."

\section{DISCUSSÃO}

O parto, sendo um procedimento hospitalar, deve ser conduzido seguindo o Código de Ética Médica (2010), que consta em seu Artigo 34 que é vedado ao médico: Deixar de informar ao paciente o diagnóstico, o prognóstico, os riscos e os objetivos do tratamento, salvo quando a comunicação direta possa lhe provocar danos, devendo, nesse caso, fazer a comunicação a seu representante legal. A partir deste se pode verificar que já nas consultas pré-natais com a médica-ginecologista que Mariana não recebeu as devidas informações a respeito dos possíveis riscos de um parto normal, mesmo diante de vários questionamentos a médica não fornece 
informações suficientes, e isso lhe traz angústias já que possuía previamente crenças de que a sua idade não era a mais adequada para uma gestação.

O parto de Mariana foi idealizado por ela e tudo transcorria de forma tranquila e dentro do que a mesma previa, até chegar aos nove $\mathrm{cm}$ de dilatação, quando é induzida a uma analgesia, sem que lhe seja explicado os resultados de tal procedimento e the permitido a escolha sobre a aplicação do medicamento. Além de perder a autonomia sobre o seu corpo, também lhe é roubado o papel principal, naquele momento os procedimentos médicos protagonizam a cena. Um estudo realizado por Palharini (2017) corrobora com esse fato ao concluir que na violência obstétrica o médico utiliza da autoridade cientifica para justificar suas condutas, tudo o que for contrário e questione sua prática é desqualificado. Aguiar (2010) complementa dizendo que a apropriação do corpo e processos reprodutivos das mulheres pelo profissional de saúde no momento do parto acaba trazendo impactos negativos na qualidade de vida das mulheres.

Outro aspecto importante que Mariana traz é sobre o significado das dores. Ela percebia que aquela dor era uma comunicação da sua filha para com ela, era a bebê avisando que estava perto do nascimento e Mariana respondia a filha trazendo uma fala consoladora. Como afirma Gutman (2013, p.95), "as mulheres não sofrem por causa das contrações. Sofrem quando ficam sozinhas, humilhadas, maltratadas, ameaçadas ou atemorizadas." Com esta fala a gente percebe que o mais doloroso não se reduz ao que é sentido no corpo, mas o que fere a dignidade e tira a autonomia. A dor das contrações para Mariana possuía um significado, e não foram elas as responsáveis pelos traumas advindos do seu parto.

Após perder seu protagonismo, Mariana tomada pelo desespero diante da chance de sua filha nascer morta, solicita a Manobra de Kristeller, neste momento seu corpo é reduzido a um objeto, um meio para se chegar ao produto, que é o bebê, ela totalmente anulada é levada ao extremo do não-pertencimento. E esse é o sentimento mais forte originado pela violência obstétrica, o de objetificação. Sobre isso Silva (2015) diz que, a objetificação das mulheres no momento do parto, expressa o quanto é negada e anulada a existência de sentimentos e afetos nesta experiência, corroborada pela atual estruturação do atendimento.

Ainda de acordo com Silva (2015) a imagem da equipe de saúde deveria estar associada a quem as mulheres no ciclo gravídico-puerperal pudessem confiar sua vida e a do bebê, expressando-se disponível e compromissada a ajudá-las nesta vivência. No entanto, isso não ocorreu no parto de Mariana, logo após o momento expulsivo a médica obstetra iniciou uma fala onde deu recomendações para que Mariana não realizasse mais partos por via normal diante dos riscos passados naquele, transferindo a ela a culpa por todo o ocorrido, além de responsabiliza-la por possíveis consequências em sua filha.

Mariana passa cerca de $6 \mathrm{~h}$ sem informação sobre o estado de saúde da bebê, e é possível imaginar como nessas horas os pensamentos permearam seu 
imaginário, reforçando a ideia de culpa. Quando finalmente consegue ter contato com a filha, suas angústias, temores, inseguranças vem à tona e fazem com que ela não experimente o amor de forma genuína. O pavor de ter causado sofrimento a bebê, ocasionado por uma culpa que não a cabia, inibiram que os sentimentos bons pudessem ser vividos, influenciando significativamente no estabelecimento do vínculo parental. Em estudo realizado por Schwab, Marth e Bergant (2012), foi feito uma avaliação do impacto do parto no desenvolvimento de transtornos em mulheres, e destacou que entre as que passaram por uma história de parto traumático, 60\% apresentaram sintomas depressivos nas primeiras semanas após o parto.

Pelo sofrimento vivido e por conhecimento da importância do psicólogo, Mariana solicita este atendimento e the é negado. Situação que confirma a ausência de escuta, tornando visível a banalização do sofrimento na assistência à saúde abordada por Aguiar e D'Oliveira (2011). O sofrimento não é legitimado, talvez pela sua naturalização no momento do parto.

A violência obstétrica pode permear todo o ciclo gravídico-puerperal, não se restringe apenas ao momento do parto. O pós-parto da entrevistada também foi marcado pela má assistência e cita o pediatra e as enfermeiras. Em relação a este fato, a pesquisa de Aguiar et. al., (2013), a qual foi feita com trabalhadores da área de saúde, traz dados que demonstram a consciência dos profissionais sobre as atitudes de violência. Mesmo sabendo que suas atitudes eram agressivas, a autora desta pesquisa explica que os entrevistados alegaram que eram "para o bem do paciente". Vimos aqui a percepção de saber absoluto por parte desses profissionais.

Outro aspecto demonstrado como fomentador da dor de Mariana, foi com relação a estrutura do hospital, o qual possuía o berçário localizado ao lado da UTI, colocando-a a exposição da felicidade de outras famílias, enquanto passava por aquele momento doloroso. Sobre este aspecto há uma resolução da ANVISA que institui ações para a promoção da segurança do paciente e a melhoria da qualidade nos serviços de saúde, a RDC n³6/2008. No entanto, nesta não há clareza sobre as regras às quais as maternidades devem se submeter, discorre sobre ações em hospitais de forma geral, porém sabe-se que o parto se constitui um procedimento médico peculiar, já que não se trata de patologia e devia ser visto sob esta ótica.

O sofrimento e sentimentos de culpa não se extinguem no retorno ao lar, Mariana peregrina por 30 dias em diversas especialidades médicas. A culpa trazia a constatação de que sua filha estivesse sequelada devido àquele momento e indiretamente devido às suas escolhas. Além disso, o receio de engravidar ocorre diante do pavor de reviver a experiência traumática. O que vimos com o relato de caso é que não houveram, além da manobra de Kristeller, outras intervenções físicas que possivelmente pudessem ocasionar lacerações no seu corpo, como em outros estudos. Os traumas e violências sofridas foram psicológicos, por isso, 
dilaceraram a sua dignidade, feriram os seus sonhos, arruinaram as suas expectativas e possibilidades do parto almejado. Talvez, por este aspecto é que esses traumas persistem até hoje, a sua cura está muito além da cicatrização de uma ferida sofrida no corpo físico.

\section{CONCLUSÃO}

Um dos resultados mais importantes deste estudo foi a visão global sobre a violência obstétrica. Em muitas pesquisas o enfoque é dado às intervenções físicas, procedimentos que os médicos utilizam para acelerar o processo de parto e que trazem sofrimento a gestante. Aqui, no entanto, se pôde ter a constatação de que a violência obstétrica se dá num conjunto de negligências, incluindo desde o acolhimento pela equipe médica até a estrutura do hospital.

Durante todo relato de parto, a entrevistada se emociona ao relembrar as cenas, sentimentos de insegurança, culpa e frustração, foram desencadeados diante das violências sofridas. Além disso, negligenciaram as suas dores, trataram com descaso o seu sofrimento. Verifica-se também, que independente do nível de conhecimento da mulher, o seu corpo no parto, não está submetido aos seus desejos, ela não terá autonomia, o saber médico é o protagonista e para o parto ser ideal à mulher, é preciso atribuir a ela o papel principal.

É possível perceber que este momento é único para cada mulher, e para cada uma há a melhor forma de parir. A analgesia que dificultou o processo de parturição de Mariana, serve para aliviar a dor e ajudar outras mulheres, por isso, não cabe no parto um protocolo de procedimentos a serem seguidos, como no caso das patologias. Distinguir que apesar do parto, na maioria das vezes, ocorrer em hospitais, ele não se configura um estado doentio.

Um parto violento pode causar traumas que impactam a vida da vítima. No caso de Mariana, não viver de forma plena este momento, dificultou o seu vínculo com a filha, a fez viver sentimentos depressivos no pós-parto, além de não lhe permitir que engravide novamente. Vale salientar que quando falamos em consequência, não necessariamente elas devem ocorrer muito após o fato, ou seja, Mariana foi vítima da violência obstétrica e os sentimentos advindos daquele momento foram sentidos por ela ainda na maternidade.

Com o intuito de contribuir na qualidade da assistência prestada a gestante, este estudo nasceu e espera esclarecer que a humanização é imprescindível, desde o pré até o pós-natal. Faz-se urgente entender que a violência obstétrica não se restringe apenas ao uso de práticas intervencionistas, mas abarca desde a atitude do profissional de saúde até a estruturação física do hospital. Além disso, almeja trazer a visão de singularidade a cada parto, tornando a mulher protagonista, fazendo-a viver de forma plena este momento. Abre margem para futuros estudos 
no que concerne ao quão os aspectos citados, como estrutura hospitalar por exemplo, pode influenciar na experiência de parto.

\section{REFERÊNCIAS}

ANDRADE, B. P.; AGGIO, C. M. Violência Obstétrica: a dor que cala. Anais do III Simpósio Gênero e Políticas Públicas. Universidade Estadual de Londrina, 27 a 29 de Maio de 2014.

AGUIAR, J.M. et al. Violência institucional, autoridade médica e poder nas maternidades sob a ótica dos profissionais de saúde. Caderno de Saúde Pública, Rio de Janeiro, p. 2287-2296, nov. 2013.

AGUIAR, J.M. Violência institucional em maternidades públicas: hostilidade ao invés de acolhimento como uma questão de gênero. 2010. Tese (Doutorado) - Faculdade de Medicina, Universidade de São Paulo, São Paulo. 2010.

AGUIAR, J. M.; D' OLIVEIRA, A. F. P. L. Violência institucional em maternidades públicas sob a ótica das usuárias. Interface Comunicação Saúde Educação, v. 15, n. 36, p. 79-92, mar, 2011.

BEZERRA, M. G. A.; CARDOSO, M. V. L. M. L. Fatores culturais que interferem nas experiências das mulheres durante o trabalho de parto. Revista Latino-americana de Enfermagem, [s.l.], v. 14, n. 3, p.414-421, jun. 2006.

BRASIL. Programa de Humanização do Pré Natal e Nascimento. Brasília (DF): Ministério da Saúde, 2000.

BRASIL. Oito passos para maternidade segura. Guia Básico para os Serviços de Saúde. Brasília (DF): Ministério da Saúde, 1996.

BRASIL. Resolução de Diretoria Colegiada. Brasília (DF): Agência Nacional de Vigilância Sanitária, 2013.

CAJUEIRO, R. L. P. Manual para elaboração de trabalhos acadêmicos: guia prático do estudante. Petrópolis: Vozes, 2015. 112 p.

CARVALHO, V. F. et al. Como os trabalhadores de um Centro obstétrico justificam a utilização de práticas prejudiciais ao parto normal. Revista da Escola de Enfermagem da Usp, São Paulo, v. 1, n. 46, p.32-35, jun. 2012.

CHAUÍ M. Repressão sexual: essa nova [des] conhecida. São Paulo (SP): Brasiliense; 1991. 
CONSELHO FEDERAL DE MEDICINA (CFM - Brasil). Código de ética médica. Resolução n 1.246/88. Brasília: Tablóide, 1990.

COSTA, S.M. et al. Episiotomia: o que há de verdade neste tradicional procedimento? Femina. 29 (4), 201-03, mai. 2001.

CUNHA, C.C.A. Violência obstétrica: uma análise sob o prisma dos direitos fundamentais. 2015. 46f. Monografia (Bacharelado em Direito) - Universidade de Brasília, Brasília, 2015.

DAVIS-FLOYD, R. The technocratic body: american childbirth as cultural expression. Social Science and Medicine, v. 38, n. 8, p. 1125-1140, 1994.

DINIZ, C.S.G. Humanização da assistência ao parto no Brasil: os muitos sentidos de um movimento. Ciência \& Saúde Coletiva, 10(3), 627-637, 2004.

DINIZ, C.S.G.; CHACHAM, A.S. O 'corte por cima' e o 'corte por baixo': o abuso de cesáreas e episiotomias em São Paulo. Questões de Saúde Reprodutiva, v.1, n.1, p.80-91, 2006.

Escola Nacional de Saúde Pública. Inquérito Epidemiológico sobre as consequências do parto cesárea desnecessário no Brasil. Projeto Nascer no Brasil. [Internet]. 2014.

GUTMAN. L.; Mulheres visíveis, mães invisíveis. Rio de Janeiro. Ed: Best seller. 2013.

JUÁREZ, DIANA Y OTRAS. Violencia sobre las mujeres: herramientas para el trabajo de los equipos comunitarios /Diana Juárez y otras.; edición literaria a cargo de Ángeles Tessio. - la ed. - Buenos Aires: Ministerio de Salud de la Nación, 2012.

LEAL, M.C. et al. Intervenções obstétricas durante o trabalho de parto e parto em mulheres brasileiras de risco habitual. Cadernos de Saúde Pública. 2014, v 30, 17-47.

LEISTER, N. Transformações no modelo assistencial ao parto: história oral de mulheres que deram à luz nas décadas de 1940 a 1980. 2011 . 174 f. Tese (Doutorado) - Curso de Enfermagem, Escola de Enfermagem, Universidade de São Paulo, São Paulo, 2011.

MINAYO, M. C. S. O desafio do conhecimento: pesquisa qualitativa em saúde. 14. ed. São Paulo: Hucitec, 2014.

OBERG, $V$. The amniotomy question: examining the pros and cons of rupturing membranes. Midwifery Today Int Midwife. n. 95, 201, p. 9-10, 2010.

ODENT, M. O camponês e a parteira: uma alternativa à industrialização da agricultura e do parto. Tradução de Sarah Bauley. São Paulo (SP): Ground, 2003. 
Organização Mundial da Saúde. Maternidade segura. Assistência ao parto normal: um guia prático. Genebra: OMS, 1996.

OSIS, M. J. M. D. PAISM: um marco na abordagem da saúde reprodutiva no Brasil. Cadernos de Saúde Pública, v. 14, Supl. 1, p. 25-30, 1998.

PALHARINI, L. A. Autonomia pra quem? O discurso médico hegemônico sobre a violência obstétrica no Brasil. Unicamp. Campinas (SP), 2017.

PROGIANT, J.M.; PENNA L.H.G., CHRISTOFEL M. Parto e nascimento: reflexões de enfermeiras obstétricas. Revista Enfermagem Atual, p. 23-26, 2004.

RATTNER, D. Humanización en la atención a nacimientos y partos: breve referencial teórico. Interface - Comunic., Saúde, Educ., v.13, supl.1, p. 595-602, 2009.

REZENDE FILHO, J; MONTENEGRO, C.A.B. Obstetricia Fundamental. Rio de Janeiro/; Guanabara Koogan, 2013.

SCHWAB, W.; MARTH, C.; BERGANT, A.M. Post traumatic stress disorder post partum. Geb. Fra. Science, v. 72, p. 56-63, 2012.

SILVA, A. B. "Ser tratada como lixo. É normal?": a experiência de mulheres vítimas de violência obstétrica. 2015. 44 p. Monografia (Psicologia). Universidade Católica de Brasília. Taguatinga/DF, 2015.

SOUZA, A.S.R. et al. Indução do trabalho de parto: conceitos e particularidades. FEMINA, Abril, vol. 38, n 4, 2010.

TURATO, E. R. Tratado da metodologia da pesquisa clínicoqualitativa: construção teórico-epistemológica, discussão comparada e aplicação nas áreas da saúde e humanas. Petrópolis: Vozes, 2011 , p. 361.

ZANETTI, M.R.D.; PETRICELLI, C.D.; ALEXANDRE, S.M., TORLONI, M.R.; MARIA, R.T., NAKAMURA, U.M.; SASS, N.S. Episiotomia: revendo conceitos. FEMINA. 2009; 37 (7).

WOLFF, L. R.; WALDOW, V. R. Violência Consentida: mulheres em trabalho de parto e parto. Saúde e Sociedade. São Paulo, v. 17, n. 3, p. 138-151, 2008.

Recebido em: 17/08/2018.

Aceito em: 31/05/2019. 